Https://online.unisc.br/seer/index.php/cadpesquisa

ISSN on-line: $1677-5600$

Doi: $10.17058 / c p . v 31 i 1.13012$

Universidade de Santa cruz do Sul - Unisc

Recebido em 05 de Janeiro de 2019 Aceito em 13 de Março de 2019 Autor para contato: diegoprado@unisc.br

\title{
Potencial produtivo de forrageiras estivais perenes e anuais, no sul do Brasil
}

Production potential of perennial and annual summer forages in southern Brazil

\author{
Andressa Bruna Vasum \\ Geovane Ruschel \\ Jonas Schleicher \\ Jonas Marcelo Ramon \\ Cláudia Klein \\ Universidade do Oeste de Santa Catarina - UNOESC - Joaçaba - Santa Catarina - Brasil \\ Diego Prado de Vargas \\ Universidade de Santa Cruz do Sul - UNISC - Santa Cruz do Sul - Rio Grande do Sul - Brasil
}

\section{Resumo}

A utilização de pastagens para a alimentação de ruminantes auxilia na diminuição dos custos de produção, aumentando a viabilidade da atividade. Com o objetivo de avaliar o potencial de produção de matéria seca (MS) e teores de proteína bruta (PB) de pastagens estivais perenes e anuais no sul do Brasil, conduziu-se um experimento fatorial em blocos casualizados, com 5 repetições de quatro forrageiras estivais, duas anuais (Milheto ou Pennisetum glaucum (L.) R. BR. e capim Sudão ou Sorghum bicolor cv. sudanense), e 2 perenes (Jiggs ou Cynodon dactilon sp. cv. Jiggs e Braquiária mulato II ou Brachiaria hibrida cv. Mulato II), totalizando 20 parcelas de 2,25 m2 (1,5m x 1,5m), com um metro de espaçamento entre si. Através de um quadrado de $0,25 \mathrm{~m}^{2}(50 \mathrm{~cm} \times 50 \mathrm{~cm})$, lançado aleatoriamente em cada parcela, foram coletadas através de simulação de pastejo, amostras das cultivares, que foram analisadas quanto a produção de MS e teores de PB. Verificou-se maior potencial de produção em MS e teores médios de PB nas pastagens estivais perenes. O Jiggs apresentou uma produção acumulada em 4 cortes de $14.528 \mathrm{Kg}$ de MS/ha e teores médios de PB de $11,35 \%$. A Braquiária mulato II mostrou o melhor rendimento produtivo no segundo corte $(4.036 \mathrm{x}$ $3.492 \mathrm{~kg}$ de $\mathrm{MS} / \mathrm{ha})$ e teores médios de $\mathrm{PB}(10,28 \%)$ maiores que as pastagens estivais anuais, no entanto atingiu sua altura ideal de coleta somente em dois momentos (primeiro e segundo corte).

\section{Abstract}

The use of pastures to feed ruminants helps to reduce production costs, increasing the viability of the activity. In order to evaluate the potential of dry matter (DM) and crude protein (CP) levels of summer perennial and annual forages in southern Brazil, a randomized complete block design with 5 replicates of four summer forages, annual (Pearl millet or Pennisetum glaucum (L.) R. BR. e Sudan grass or Sorghum bicolor cv. sudanense), and two perennials (Jiggs grass or Cynodondactilon sp. cv. Jiggs and Mulato II Hybrid Brachiaria or Brachiaria hibrida cv. Mulato II), totaling 20 plots of $2.25 \mathrm{~m} 2$ $(1.5 \mathrm{~m} \times 1.5 \mathrm{~m})$, with one meter of spacing between them.Through a square of $0.25 \mathrm{~m}^{2}(50 \mathrm{~cm} \times 50$ $\mathrm{cm})$, randomly placed in each plot, were collected through grazing simulation, samples of the cultivars, which were analyzed to produce DM and CP contents. It was verified a greater potential of production in DM and average levels of $\mathrm{CP}$ in the summer pasturesperennial. The Jiggs grass presented a cumulative production in four cuts of $14,528 \mathrm{~kg}$ of DM / ha and average of CP of $11.35 \%$. The Mulato II Hybrid Brachiaria showed the best productive yield in the second cut $(4,036 \times 3.942 \mathrm{~kg}$ of DM / ha) and mean values of PB $(10,28 \%)$ higher than the summer pasturesannual, however reaching its ideal height of collection only in two moments (first and second cut).

\section{Palavras-chave}

Braquiária mulato II. Capim Sudão. Jiggs. Milheto. Pastagens.

\section{Keywords}

Mulato II Hybrid Brachiaria. Sudan grass. Jiggs grass. Pearl millet. Pasture. 


\section{Introdução}

O Brasil possui o maior rebanho bovino comercial do mundo, porém dispõe de baixos índices de produtividade (IBGE, 2014). Nesse sentido, um dos principais entraves para a melhoria da produção nacional está relacionado com a alimentação dos animais, na qual as pastagens cultivadas possuem grande destaque.

A produção de leite ou carne, utilizando como principal alimento a pastagem, é uma das melhores e mais eficientes formas de se reduzir os custos de produção, principalmente em períodos onde ocorrem altas nos preços de concentrados (BARCELLOS et al., 2008).

Conforme Corrêa e Santos (2003), nas regiões de clima tropical e subtropical, há grande potencial de produção, com várias gramíneas forrageiras bem adaptadas, tais como as dos gêneros Panicum, Brachiaria, Cynodon e Pennisetum que, se bem manejadas, podem constituir o principal componente da dieta de ruminantes.

Nesse contexto, as condições climáticas da região sul do Brasil, com chuvas bem distribuídas, permitem a utilização de espécies forrageiras de distintos ciclos produtivos (estivais ou hibernais) e tempos de duração (perenes ou anuais) (MACHADO, 2012).

As pastagens estivais perenes são aquelas que concentram sua produção nas estações quentes do ano, e sua população de plantas se perpetuará de forma voluntária, na mesma área pastoril, por no mínimo três anos consecutivos, caso contrário, podem ser consideradas espécies anuais e precisarão ser replantadas a cada ano (ORTH et al., 2012; AGUIRREet al., 2014).

O Milheto (Pennisetum glaucum (L.) R. BR.) e o capim Sudão (Sorghum bicolor cv. sudanense) estão entre as forrageiras estivais anuais mais cultivadas no sul do Brasil, pois possuem crescimento rápido e elevado valor nutritivo no tecido vegetal imaturo (ORTH et al., 2012). Já entre as estivais perenes, destacam-se na região sul do país as do gênero Cynodon, como o Jiggs (Cynodon dactilon sp. cv. Jiggs) e no território nacional as do gênero Brachiaria, como a Brachiaria hibrida cv. Mulato II, um híbrido tetraploide, resultante de três gerações de cruzamentos e seleção (REZENDE et al., 2015; TEIXEIRA et al., 2018).

A preferência pela implantação de pastagens estivais perenes em detrimento as pastagens estivais anuais, pode resultar em benefícios econômicos, de conservação do solo, e consequentemente da qualidade e quantidade de forragens ofertadas aos animais.

Com o desenvolvimento da pecuária moderna e competitiva, onde as margens de retorno cada vez são menores, torna-se necessário avaliar a produtividade de matéria seca (MS) e dos teores de proteína bruta (PB) das principais forrageiras estivais perenes e anuais utilizadas na região sul do Brasil, com o objetivo de auxiliar a escolha dos técnicos e produtores rurais.

\section{Material e métodos}

O experimento foi realizado durante o período de outubro de 2014 até março de 2015, em uma área de $150 \mathrm{~m}^{2}$, localizada na latitude 26o 15' 46.07' Sul e longitude 53 31' 51.49" Oeste, com altitude de 575 metros do nível do mar, na cidade de Barracão, no estado do Paraná, sul do Brasil. Segundo a classificação climática de Köppen, utilizando a série de dados do Instituto Agronômico do Paraná (IAPAR) até 1998, a área experimental foi classificada em clima Cfa (Clima subtropical), com temperatura média no mês mais frio inferior a $18^{\circ} \mathrm{C}$ 
(mesotérmico) e no mês mais quente acima de $22^{\circ} \mathrm{C}$, com verões quentes, geadas pouco frequentes e tendência de concentração das chuvas nos meses de verão, contudo sem estação seca definida.

O solo onde foi conduzido o experimento é classificado como Latossolo Vermelho, sendo definido pelo Sistema Brasileiro de Classificação de Solos (SIBCS, 2000), pela presença de horizonte diagnóstico latossólico e características gerais como: argilas com predominância de óxidos de ferro, alumínio e silício, argilas de baixa atividade (baixa capacidade de troca de cátions, CTC), fortemente ácidos e baixa saturação de bases (SANTOS e ZARONI, 2014).

A área de implantação do ensaio foi dessecada com o herbicida $\mathrm{N}$-(fosfonometil) glicina, produto não seletivo de ação sistêmica do grupo químico glicina. Nesse sentido, foi aplicado um volume de três litros de herbicida e 170 litros de calda por hectare através de equipamento costal com acionamento manual e ponta AXI 110015 (M015). A dessecação foi feita 50 dias antes da implantação e 10 dias de antecedência da semeadura e plantio das espécies forrageiras.

Após, foi feita a subsolagem e posterior gradagem superficial, para nivelamento do solo e eliminação de torrões de dimensões maiores. A gradagem foi realizada com auxílio de grade aradora, e também serviu para a incorporação do fósforo e do potássio, cuidando-se para que a realização do procedimento fosse no sentido transversal à declividade do terreno, com objetivo de diminuir a possibilidade de erosão.

Os resultados referentes a análise do solo na área experimental, foram obtidos em amostragens de 0 a $20 \mathrm{~cm}$ de profundidade, em 18 repetições, obtendo-se pH em água de 5,6, argila de 46,25\%, saturação por bases (V\%) de 64,97\%, matéria orgânica de $50,34 \mathrm{~g} / \mathrm{dm}^{3}$, alumínio de $0,0 \mathrm{cmol}_{c} / \mathrm{dm}^{3}$, potássio de $0,95 \mathrm{cmol}_{c} / \mathrm{dm}^{3}$ e capacidade de troca de cátions (CTC) de $17,75 \mathrm{cmol}_{\mathrm{c}} / \mathrm{dm}^{3}$.

A adubação foi realizada conforme análise e interpretação pelo manual de adubação e calagem para os estados do RS/SC 2004, seguindo a recomendação, conforme os níveis presentes no solo e fornecimento de nutrientes necessários para a expectativa de produção de $25 \mathrm{t} \mathrm{MS/ha,} \mathrm{com} \mathrm{adições} \mathrm{para} \mathrm{cada} \mathrm{tonelada} \mathrm{de} \mathrm{matéria} \mathrm{seca} \mathrm{esperada,} \mathrm{que} \mathrm{exceda} \mathrm{as} 12$ toneladas por hectare.

Posteriormente foi realizada a adubação com NPK na área experimental, totalizando 490 $\mathrm{kg} / \mathrm{ha}$ de $\mathrm{N}$ (nitrato de amônia na base e ureia em superfície), $250 \mathrm{~kg} / \mathrm{ha}$ de $\mathrm{P}$ (super fosfato triplo aplicado na base) e $260 \mathrm{~kg} / \mathrm{ha}$ de $\mathrm{K}$ (cloreto de potássio no momento da implantação das forrageiras).

A semeadura e plantio foram realizadas em outubro de 2014, de acordo com o zoneamento agrícola para o estado do Paraná e recomendações técnicas da cultura, sendo a cultura antecessora da área, a grama sempre-verde ou curitibana (Axonopus compressus (Sw.) P.Beauv.).

O experimento foi conduzido através de arranjo fatorial em blocos casualizados, com 5 repetições de quatro forrageiras estivais, duas anuais (capim Sudão e Milheto) e 2 perenes (Braquiária mulato II e Jiggs), totalizando 20 parcelas de $2,25 \mathrm{~m}^{2}$ (1,5m x 1,5m), com um metro de espaçamento entre si.

Primeiramente realizou-se a demarcação das parcelas, deixando os espaços para corredores entre as mesmas, para em seguida implantar as cultivares por semente: Milheto, Braquiária mulato II e capim Sudão. Posteriormente propagou-se por mudas, a cultivar Jiggs. 
Para a implantação das espécies por semente, realizou-se a abertura de pequenos sulcos para posterior semeadura manual, em densidades de $40 \mathrm{~kg}$, $50 \mathrm{Kg}$ e $12 \mathrm{Kg}$ de sementes/ha, para o capim Sudão, Milheto e Braquiária mulato II, respectivamente.

Para a cultivar Jiggs utilizou-se a recomendação de 40 mil mudas/ha. As mudas foram coletadas a campo em uma plantação já estabelecida, onde priorizou-se àquelas com nove estolões e enraizadas, para uma melhor e mais rápida propagação, sem a interferência de pragas e doenças. Os estolões foram removidos manualmente, para em seguida efetuar-se a implantação no local. O espaçamento utilizado foi de $0,5 \mathrm{~m} \times 0,5 \mathrm{~m}$, e os sulcos abertos com enxada, totalizando nove mudas por parcela.

$\mathrm{Na}$ área do experimento realizou-se duas capinas, com a finalidade de eliminar plantas daninhas e também duas aplicações de herbicida para limpeza dos corredores e arredores. No período de realização do experimento não houve a necessidade de interferência com inseticidas, devido a ausência de pragas e doenças.

Através de um quadrado de $0,25 \mathrm{~m}^{2}(50 \mathrm{~cm} \times 50 \mathrm{~cm})$, lançado aleatoriamente em cada parcela, foram coletadas através de simulação de pastejo as cultivares Milheto, Braquiária mulato II, capim Sudão e Jiggs, quando apresentaram sua altura de corte ideal ou atingiram sua maturidade fisiológica. As alturas dos resíduos foram específicas para propiciar um adequado rebrote, conforme Tabela 1. Após a coleta, realizou-se o corte do restante da parcela, com o auxílio de uma roçadeira costal.

Nas amostras obtidas, foi realizada a determinação dos teores de matéria seca (MS) e proteína bruta (PB), segundo metodologias da AOAC (1996, métodos 967.03 e 942.05, respectivamente).

Os dados meteorológicos diários das temperaturas mínimas e máximas, e precipitação pluviométrica mensal, referentes ao período experimental foram obtidos na Empresa de Pesquisa Agropecuária e Extensão Rural (EPAGRI), situada em Dionísio Cerqueira, no estado de Santa Catarina, a partir da estação climática em Barracão, no estado do Paraná (Tabela 2).

Os resultados de acúmulo de matéria seca e proteína bruta por hectare nos diferentes cortes, foram submetidos à análise de variância univariada (ANOVA), e as médias comparadas pelo teste de Tukey ao nível de $5 \%$ de significância. As análises estatísticas foram executadas no aplicativo SISVAR.

\section{Resultados e discussões}

Na avaliação da produção de massa seca por corte, na cultivar Braquiária mulato II foi possível realizar somente duas coletas, devido ao seu desenvolvimento inicial lento, atingindo a altura ideal de coleta somente no primeiro e segundo corte. Essa cultivar apresentou baixo desempenho no período experimental, ou seja, aproximadamente $50 \%$ da produção de massa seca da cultivar Jiggs (Tabela 3). Isto, em conjunto ao seu maior período de estabelecimento e intervalo entre cortes, demonstra que a Braquiária mulato II não é uma opção viável para as condições do sul do Brasil. No entanto, segundo Argel et al. (2007), com a forrageira já implantada no local, é possível que as produções sejam mais elevadas, pois o seu sistema radicular estaria mais desenvolvido, acelerando o desenvolvimento inicial para o primeiro corte, o que tornaria essa cultivar uma alternativa a ser considerada, devido a sua alta produção por corte (Tabela 3). 
As produções de MS por corte encontradas nas pastagens anuais foram inferiores as obtidas nas perenes (Tabela 3). Também são inferiores aos mostrados por Fontaneli et al. (2009), que durante o período vegetativo das cultivares de Milheto e capim Sudão (aproximadamente de 120 a 150 dias), observaram valores de 15 toneladas de MS/ha/ano e Rezende et al. (2015), que evidenciaram produção superior a 20 toneladas de MS/ha/ano para os Cynodons. Os menores valores de produções de MS encontrados nesse ensaio podem estar relacionados as baixas precipitações observadas nos meses de outubro, novembro e fevereiro (Tabela 2).

Considerando-se a soma da produção de MS das forrageiras em todos os cortes, constata-se que a cultivar Jiggs teve superioridade sobre as demais, seguida pelas cultivares anuais Milheto e capim Sudão, e por último a forrageira perene Braquiária mulato II (Tabela 3).

Analisando a produção de MS entre as cultivares, os maiores teores encontrados foram no segundo corte para todas as forrageiras. Segundo Fontaneli et al. (2009), isto se deve ao melhor desenvolvimento do sistema radicular das cultivares nesse período e do elevado número de perfilhos provocados pelo primeiro corte (Tabela 3 ).

A qualidade de um volumoso oferecido aos animais está diretamente ligada a lucratividade do sistema produtivo, bem como na sustentabilidade de uma determinada atividade, desta forma os teores de PB encontrados nas forrageiras é fundamental para 0 balanceamento da dieta dos ruminantes, e determinar a qualidade do volumoso.

Verifica-se que a cultivar Jiggs apresentou os maiores teores médios de PB, chegando a $12,57 \%$ no primeiro corte (Tabela 4). Isto pode ser explicado pelas sua características individuais, como uma boa relação de folhas e colmos (POCZYNEK et al., 2016), e pela verificação do ponto ideal da simulação de pastejo, obtendo-se índices considerados satisfatórios para a região de estudo. Estes resultados estão em conformidade com os encontrados por Rezende et al. (2015), que em solos de boa fertilidade e manejo adequado, encontraram teores de $11 \%$ a $13 \%$ de PB para os Cynodons.

A segunda forrageira com melhores resultados quanto aos teores médios de PB foi a cultivar Braquiária mulato II, com uma produção média de $10.28 \%$ de PB (Tabela 4). Estes resultados são semelhantes aos encontrados por ARGEL et al. (2007) (11,4\%).

Por fim, os menores resultados obtidos para os teores médios de PB foram oriundos das gramíneas estivais anuais Milheto e capim Sudão (Tabela 4).

Analisando a PB das cultivares nos diferentes cortes, nota-se que em todas as forrageiras, os maiores teores encontrados foram no primeiro corte. Segundo Cano et al. (2004), isto se deve aos menores teores de fibras e ligninas nos colmos, e também a boa relação folha/colmo quando comparado com os cortes subsequentes. Dessa forma, com a pastagem em pleno desenvolvimento se tem um percentual de PB maior no primeiro corte.

Além disso, sabe-se que o quanto antes as pastagens cobrirem o solo menor será a probabilidade de ocorrer problemas com erosão, além da antecipação da oferta de forragem para os animais, reduzindo os custos com insumos externos nas propriedades (ARGEL et al., 2008). As forrageiras que se destacaram nesse quesito foram as estivais anuais Milheto e capim Sudão, onde para as duas cultivares a primeira simulação de pastejo foi realizada 62 dias após implantação (Tabela 3).

No entanto, tendo em vista que as cultivares perenes já estarão implantadas em anos posteriores e o seu sistema radicular estará com desenvolvido adequado, essas forrageiras em condições favoráveis de temperatura e umidade já iniciarão seu desenvolvimento, o que 
coincindirá provavelmente com a primavera, período este considerado crítico na região sul do Brasil, devido ao vazio forrageiro das pastagens. Assim, pensando em produções futuras, as forrageiras perenes irão atingir ponto ideal de pastejo antes que as anuais.

\section{Conclusões}

Verificou-se maior potencialidade de produção em MS e teores médios de PB nas pastagens estivais perenes, destacando-se o Jiggs com uma produção acumulada em 4 cortes de $14.528 \mathrm{Kg}$ de MS/ha e teores médios de PB de 11,35\%. Nesse sentido, sugere-se a utilização de cultivares estivais perenes, em detrimento das anuais, pois resultariam em benefícios econômicos, de conservação do solo, e em anos posteriores, com seus sistemas radiculares mais desenvolvidos, e em condições favoráveis de temperatura e umidade já iniciariam seu desenvolvimento, o que coincindiria provavelmente com a primavera, período considerado crítico na região sul do Brasil, devido ao vazio forrageiro das pastagens.

\section{Referências}

1. AGUIRRE, P.F.; OLIVO, C.J.; SIMONETTI, G.D.; NUNES, J.S.; SILVA, J.O.; SANTOS, M.S.; CORREA, M. R.; BRATZ, V.F.; ANJOS, A.N.A. Produtividade de pastagens de Coastcross-1 em consórcio com diferentes leguminosas de ciclo hibernal. Ciência Rural, n.12, p.22652272, 2014.

2. ARGEL, P.J. et al. 2007. Cultivar Mulato II (Brachiaria híbrida CIAT 36087): Gramínea de alta qualidade e produção forrageira, resistente às cigarrinhas e adaptadas a solos tropicais ácidos. Cali, Colômbia: CIAT. 22 p.

3. ASSOCIATION OF OFFICIAL ANALYTICAL CHEMISTS (AOAC), 1996. Official Methods of Analysis, 16th ed. AOAC, Washington, DC, USA.

4. BARCELLOS, A.O.; RAMOS, A.K.B.; VILELA, L.; MARTHA JUNIOR, G.B. Sustentabilidade da produção animal baseada em pastagens consorciadas e no emprego de leguminosas exclusivas, na forma de banco de proteína, nos trópicos brasileiros. Revista Brasileira de Zootecnia, v.37, suplemento especial, p.51-67, 2008.

5. CANO, C.C.P.; CANTO, M.W.; SANTOS, G.T.; GALBEIRO, S. MARTINS, E.N.; MIRA, R.T. Valor nutritivo do capim-Tanzânia (Panicum maximum Jacq. cv. Tanzânia-1) pastejado em diferentes alturas. Revista Brasileira de Zootecnia, v.33, n.6, supl.2, p. 1959- 1968, 2004.

6. CORREA, L.A.; SANTOS, P.M. Manejo de utilização de plantas forrageiras dos gêneros Panicum, Brachiaria e Cynodon. São Carlos: Embrapa, 2003. 36 p.

7. COSTA, K.A.P.; ROSA, B.; OLIVEIRA, I.P.; CUSTÓDIO, D.P.; SILVA, D.C. Efeito da estacionalidade na produção de matéria seca e composição bromatológica da Brachiaria brizantha cv. Marandu. Ciência Animal Brasileira, v.6, p.187-193, 2005.

8. FONTANELI, R.S. et al. 2009. Forrageiras para Integração Lavoura-Pecuária-Floresta na região Sul-Brasileira. 1 ed. Passo Fundo: Embrapa Trigo. 340 p.

9. MACHADO, L.A.Z. Misturas de forrageiras anuais e perenes para sucessão à soja em sistemas de integração lavoura-pecuária. Pesquisa Agropecuária Brasileira, v.47, n.4, p.629-636, 2012.

10. ORTH, R.; FONTANELI, R.S.; FONTANELI, R.S.; SACCARDO, E. Produção de forragem de gramíneas anuais semeadas no verão. Ciência Rural, v.42,n.9, p.1535-1540, 2012. 
11. POCZYNEK, M.; NEUMANN, M.; HORST, E.H.; LEÃO, G.F.M.; POCZYNEK, M.;UENO, R.K. Capacidade produtiva e qualidade nutricional de gramíneas perenes submetidas a sistema contínuo de cortes. Arquivo Brasileiro de Medicina Veterinária e Zootecnia, v.68, n.3, p.785-794, 2016.

12. REZENDE, A.V.F.; RABÊLO, H.S.; RABELO, C.H.S.; LIMA, P.P.; BARBOSA, L.A.; ABUD, M.C.; SOUZA, F.R.C. Características estruturais, produtivas e bromatológicas dos capins Tifton 85 e Jiggs fertilizados com alguns macronutrientes. Semina: Ciências Agrárias, v.36, n.3, p.1507-1518, 2015.

13. SBCS - Sociedade Brasileira de Ciência do solo. Manual de adubação e de calagem para os estados do Rio Grande do Sul e Santa Catarina. 2004. Porto Alegre: Comissão de Química e Fertilidade do Solo. 400 p.

14. TEIXEIRA, S.O.; TEIXEIRA, R.O.; SANTOS, V.B.; CARVALHO, M.A.C.; YAMASHITA, O.M. Doses de fósforo e nitrogênio na produção de Brachiaria hibrida cv. Mulato II. Revista Ceres, v.65, n.1, p. 28-34, 2018.

Tabela 1 - Alturas em centímetros $(\mathrm{cm})$ da realização do método de simulação de pastejo e do resíduo após os cortes realizados nos diferentes cultivares estivais perenes e anuais.

\begin{tabular}{lcc}
\hline \multirow{2}{*}{ Cultivares } & \multicolumn{2}{c}{ Simulação de pastejo } \\
\cline { 2 - 3 } & Altura de corte $(\mathrm{cm})$ & Altura de resíduo $(\mathrm{cm})$ \\
\hline capim Sudão & 40 & 10 \\
Milheto & 60 & 20 \\
Jiggs & 30 & 7 \\
Braquiária mulato II & 70 & 25 \\
\hline
\end{tabular}

Tabela 2 - Temperaturas mínimas e máximas em graus Celsius $\left({ }^{\circ} \mathrm{C}\right)$, e precipitação pluviométrica em milímetros $(\mathrm{mm})$, do período experimental.

\begin{tabular}{|c|c|c|c|}
\hline \multirow{2}{*}{ Mês (ano) } & \multicolumn{2}{|c|}{ Temperatura $\left({ }^{\circ} \mathrm{C}\right)^{*}$} & \multirow{2}{*}{ Precipitação $(\mathrm{mm})^{*}$} \\
\hline & Mínima & Máxima & \\
\hline Outubro (2014) & 16 & 34 & 28,0 \\
\hline Novembro (2014) & 17 & 32 & 37,0 \\
\hline Dezembro (2014) & 11 & 33 & 335,5 \\
\hline Janeiro (2015) & 18 & 34 & 383,5 \\
\hline Fevereiro (2015) & 18 & 34 & 70,0 \\
\hline Março (2015) & 16 & 32 & 90,0 \\
\hline
\end{tabular}

*Dados meteorológicos obtidos na Empresa de Pesquisa Agropecuária e Extensão Rural (EPAGRI), a partir da estação climática de Barracão (PR). 
Tabela 3 - Dias de estabelecimento até o primeiro corte, produção de matéria seca (MS) nos distintos cortes e total, em quilogramas por hectare $(\mathrm{Kg} / \mathrm{ha})$, nos diferentes cultivares estivais perenes e anuais.

\begin{tabular}{lcccccc}
\hline \multirow{2}{*}{\multicolumn{1}{c}{ Cultivares }} & \multirow{2}{*}{ Estabelecimento } & \multicolumn{5}{c}{ Cortes } \\
\cline { 3 - 6 } & & $1^{\circ}$ corte & $2^{\circ}$ corte & $3^{\circ}$ corte & $4^{\circ}$ corte & \\
\hline Capim Sudão & 62 & $2.532^{\mathrm{Dd}}$ & $3.000^{\mathrm{Ca}}$ & $2.968^{\mathrm{Bb}}$ & $2.800^{\mathrm{BC}}$ & 11.300 \\
Milheto & 62 & $2.824^{\mathrm{Cb}}$ & $2.912^{\mathrm{Da}}$ & $2.748^{\mathrm{Cd}}$ & $2.780^{\mathrm{Cc}}$ & 11.264 \\
Jiggs & 70 & $3.572^{\mathrm{Ad}}$ & $3.712^{\mathrm{Ba}}$ & $3.652^{\mathrm{Ab}}$ & $3.592^{\mathrm{Ac}}$ & 14.528 \\
Braquiária mulato II & 105 & $3.492^{\mathrm{Bb}}$ & $4.036^{\mathrm{Aa}}$ & $\mathrm{SC}^{* *}$ & $\mathrm{SC}$ & 7.528 \\
\hline
\end{tabular}

*Médias seguidas de letras diferentes minúsculas nas linhas e maiúsculas nas colunas diferem entre si pelo teste de Tukey a $5 \%$ de probabilidade.

$* * \mathrm{SC}=$ sem corte.

Tabela 4 - Porcentagem de proteína bruta (PB) nos distintos cortes, total em quilogramas de PB por hectare ( $\mathrm{Kg}$ de PB/ha) e teores médios de PB nos cortes realizados nos diferentes cultivares estivais perenes e anuais.

\begin{tabular}{|c|c|c|c|c|c|c|}
\hline \multirow{2}{*}{ Cultivares } & \multicolumn{4}{|c|}{ Cortes } & \multirow{2}{*}{ Total } & \multirow{2}{*}{ Média } \\
\hline & $1^{\circ}$ corte & $2^{\circ}$ corte & $3^{\circ}$ corte & $4^{\circ}$ corte & & \\
\hline capim Sudão & $12,03^{\mathrm{Ba}^{*}}$ & $9,84^{\mathrm{Bb}}$ & $9,13^{\mathrm{BC}}$ & $8,52^{\mathrm{Bd}}$ & $1.176,44^{\mathrm{B}}$ & $9,88^{C}$ \\
\hline Milheto & $9,53^{\mathrm{Da}}$ & $9,44^{\mathrm{Db}}$ & $7,65^{c c}$ & $7,23^{\mathrm{Cd}}$ & $952,93^{\mathrm{C}}$ & $8,46^{\mathrm{D}}$ \\
\hline Jiggs & $12,57^{\mathrm{Aa}}$ & $11,87^{\mathrm{Ab}}$ & $11,03^{\mathrm{Ac}}$ & $9,93^{\mathrm{Ad}}$ & $1.648,93^{\mathrm{A}}$ & $11,35^{\mathrm{A}}$ \\
\hline Braquiária mulato II & $10,93^{\mathrm{Ca}}$ & $9,64^{\mathrm{cb}}$ & SC** & SC & $746,73^{D}$ & $10,28^{B}$ \\
\hline
\end{tabular}

*Médias seguidas de letras diferentes minúsculas nas linhas e maiúsculas nas colunas diferem entre si pelo teste de Tukey a $5 \%$ de probabilidade.

$* * \mathrm{SC}=$ sem corte. 